\title{
6 \\ Facing the challenges of an ageing society
}

\author{
Jan Pakulski
}

Since the mid-20th century the world's population has been ageing, most noticeably in the most advanced (developed) societies, with social consequences so profound that they justify forging the concept of the 'ageing society'. The ageing society emerges as a result of, principally, low fertility rates and decreasing mortality combined with increasing longevity. Sociologists and social demographers see such a society as a harbinger of a shift to the 'fourth stage' of demographic transition, whereby birth and death rates stabilise at a low level and longevity increases (Cardwell 2006). Parallel to these processes, there are some changes in the social structure, economy, culture and politics, as well as attempts by governments to devise strategies of adaptation-cum-modification to meet the challenges posed by rapid ageing, such as a proliferation of 'ageing problems', a shrinking labour force, escalating costs of pensions and agedcare services, and social-political conservatism. Australia's relative success in facing these challenges suggests the broader applicability of a general strategic model or policy template - described below as the '4Ps' (a modification of the 3P strategy suggested in Australian Intergenerational Reports) - to other developed countries, such as Poland, that are facing the challenges of ageing. 
'Ageing society' refers to a specific type of society that emerges during demographic transition in which large shares of populations become old $(65+)$ and very old $(80+)$. Ageing societies share a number of similar challenges, such as widening individual 'problems of ageing' (poor health, loneliness, social isolation, impoverishment of old people); depletion of the labour force and an increasing dependency ratio, which together slow down growth; rising pension, aged-care and health costs and accompanying budgetary strains; and the increasing generational pressures of 'silver/grey lobbies' that contribute to rising conservatism, slow down reforms and threaten to skew the allocation of resources (e.g. United Nations 2001; Harper 2006; Harper and Hamblin 2014).

It is estimated that the proportion of such older $(60+)$ people worldwide - at present around 12 per cent-will nearly double by 2050. Even in Australia, where the total fertility rate is relatively high (1.9), and where immigration of young people also remains high, thus 'cushioning' the impact of ageing, the proportion of people aged over 65 will double by mid-century from about 13 per cent to about 27 per cent, with centenarians constituting 0.01 per cent of the total population. ${ }^{1}$ In Poland, where the process of ageing has been aggravated by a low (1.3) fertility rate and high emigration of young people, the anticipated change is more rapid and-potentially-more disruptive, with the population shrinking, an estimated 30 per cent of people reaching the retirement age by 2050, and the age dependency ratio more than doubling.

As would be expected, with the process of ageing accelerating in most developed societies, the attention paid to population ageing and the challenges that accompany it has been increasing. As the UNDESA Report (United Nations 2013) notes:

Between 2005 and 2013, the percentage of Governments that considered population ageing as a major concern has increased in more developed regions (from 76 to 92 per cent) ... [with] more than 9 out of 10 Governments in Europe and North America considering population ageing as a major concern in 2013.

1 For these and other figures see Commonwealth of Australia (2015). 
Yet, this increase is seldom accompanied by a debate about the 'population targets', as well as the nature and effectiveness of policy responses, which range from 'mitigation', typically in the form of pronatalist policies that aim at boosting fertility, to 'adaptation', typically in the form of boosting old age provisions and services. One generation after the ageing has been recognised as a source of serious challenges, there seems to be an emerging consensus that ageing poses urgent developmental and intergenerational problems, and that effective responses have to combine mitigation with adaptation, and that they have to be strategic in adopting a long-term perspective (e.g. Bloom et al. 2011; Harper and Hamblin 2014).

The trajectories of ageing, as well as the acuteness of problems that ageing engenders, differ between developed societies, but the similarities of the main challenges, as well as experiences of the initial stages of ageing, enable us to formulate some general 'lessons conclusions' in the form of a generally applicable strategic policy model. This policy model reflects the experiences and successes of Australia - a developed society that relatively successfully faces the process of ageing - but can be applied to other developed societies, especially those, like Polish society, facing more serious challenges and experiencing the problems of ageing more acutely.

Polish society is ageing fast and faces many more problems of ageing because it is ageing faster and is less affluent than Australia, and has prepared less for the demographic transition (Table 1). The median age today is 38 , and it will have increased to 51 in 2050. The demographic dependency ratio (the ratio of people 65+ compared to those aged 15-64) is predicted to shoot up from 19 per cent (2010) to 36 per cent (2030) and then to 56 per cent in 2050. The current very low fertility rate ( 1.3 births per woman) is not likely to increase, because spending on pronatal policies is very low ( 1 per cent of GDP, compared to 3.3 per cent in neighbouring Germany), high child care and childraising costs, and growing pressure on women to take employment and delay conception - or to emigrate. Poland has a much lower living standard than Australia, higher debt, and much more strain placed on the budget, and these factors limit its preparedness for ageing and restrict the field of manoeuvre for government. Yet, as argued below, 
these are problems shared, to various degrees, by all developed and ageing societies, and they do not prevent Poland from applyingwith necessary modifications - the $4 \mathrm{P}$ strategic model. ${ }^{2}$

Table 1. International comparison of social-demographic indicators: Australia and Poland

\begin{tabular}{|l|c|c|c|c|c|c|c|}
\hline Country & $\begin{array}{c}\text { TFR } \\
\text { 2005-10 }\end{array}$ & $\begin{array}{c}\text { Median } \\
\text { age } \\
\text { (years) }\end{array}$ & $\begin{array}{c}\text { Population } \\
65+(\%)\end{array}$ & $\begin{array}{c}\text { TDR } \\
(\%)\end{array}$ & $\begin{array}{c}\text { Population } \\
2010[50] \\
\text { (millions) }\end{array}$ & $\begin{array}{c}\text { AAPG } \\
(\%) \\
2005-10\end{array}$ & $\begin{array}{c}\text { LFPR } \\
2014 \\
(\%)\end{array}$ \\
\hline Australia & 1.9 & $37[45]$ & 13.4 & 48 & $24[40]$ & 1.8 & 65 \\
\hline Poland & 1.3 & $38[51]$ & 13.5 & 40 & $38[32]$ & 0.0 & 56 \\
\hline
\end{tabular}

Source: Based on Commonwealth of Australia (2015: 9) and OECD (2013).

TFR=Total Fertility Rate; TDR=Total Dependency Ratio (aged 0-14 and 65+ per 100 aged 15-64); AAPG=Annual Average Population Growth; LFPR=Labour Force Participation Rate.

The focus of this chapter is on these general policy strategiestheir overall pattern, rather than the detailed content and modes of implementation - and on the applicability of these strategies in developed societies with different ageing profiles and migration regimes. In order to highlight these strategies and discuss their broader applicability, we first discuss briefly:

- those challenges of ageing that generate the most concern and anxiety; and then

- the strategies that have been designed and partly tested with considerable success in Australia.

\section{Ageing societies and their problems}

One reason for widespread anxiety related to ageing has been poor anticipation. Until the 1980s, most social scientists in developed societies had anticipated the levelling of birth rates at or above reproduction levels, steady population growth, and even overpopulation. In fact, the mid-20th century ageing trends have proved persistent: birth rates have continued to fall throughout the late stages of modernisation, especially the Western-type modernisation that increasingly relied

2 For an overview of ageing and its social consequences in Australia, see Commonwealth of Australia (2015). For an overview in Poland see Devictor (2012) and OECD (2013). For the overall policy implication of ageing, see McDonald and Kippen (1999). For the impact of immigration on ageing in Australia, see McDonald and Kippen (2001a). 
on the occupational activisation (participation) of women, and, consequently, on the delay of marriage and child-bearing. Moreover, the initially widely acclaimed pronatalist policies have proven costly, difficult to implement, and less effective than expected, thus resulting in their half-hearted embracement and application (e.g. Kaufmann 2011). At the same time, death rates have continued their 'secular decline', and longevity has been steadily increasing, resulting in a declining proportion of young and economically active people, and an increasing proportion of the aged (65+), usually 'retirees', and the very aged $(80+)$ who increasingly suffer from dementia.

There have, of course, been some variations in the processes of ageing and its social consequences-principally between more affluent and less affluent societies, and between high immigration and low immigration ones-but the consequences of population ageing have been roughly the same in developed and developing societies, though, naturally, developed societies face these problems earlier than developing ones. The problems include, above all, the widening of 'ageing problems' (illness, loneliness, social isolation, dependency, impoverishment), shrinking of working populations combined with increasing dependency ratios (dependent/working), and increasing generational 'burdens' (rising costs of welfare and aged care, rapidly increasing health costs). All of these trends result in declining economic dynamism (diagnosed as an aspect of 'secular stagnation'), combined with the mobilisation of 'grey lobbies' and rising conservatismall exacerbated by the Great Recession hitting the advanced societies, and by the misconceived responses of some recession-traumatised governments. These responses include anti-immigration campaigns and 'deficit-cum-debt' funding of welfare and aged-care services that have proven unsustainable and that amount to intergenerational 'burden shifting' (e.g. Harper 2006; Harper and Hamblin 2014; Torp 2013; Commonwealth of Australia 2015; Summers 2014).

Due to a combination of poor anticipation, misconceived initial responses, and the constraints of the Great Recession, ageing started to transform into a set of inter-related and spiralling problems. The net effect of all these problems has been a steep stratification of societies in their vulnerability to ageing problems, and a generally increasing awareness-cum-anxiety about the problems of an ageing society. 
Five inter-related problems attract the attention of students of ageing societies. First and foremost is the high cost and dubious effectiveness of the major 'modifier' - pronatalist policies. These policies are expensive (e.g. 3.4 per cent of GDP in France; 3.9 per cent in Denmark), they often backfire (e.g. reducing participation of women in the labour force), their effectiveness differs widely, and their overall efficiency seems to depend on the design of the policy packages. Moreover, they seldom bring fertility close to the reproduction level, and are seen as only a part of the strategic policy response (e.g. Goldstone et al. 2013; Gray et al. 2008).

Second is a set of problems related to the spread - together with population ageing - of the typical afflictions of ageing: chronic illness (especially dementia and related conditions), loneliness, social isolation, dependency and impoverishment. These problems have been well diagnosed and analysed, so we add only that they are not just widening in scope, but are also gendered (women outlive men) and this requires some attention (seldom granted by decision-makers). When not tackled, these problems result in the formation of an 'aged underclass'.

Particularly worrisome - and challenging for policymakers-are problems related to the widening scope and mounting costs of aged care for dementia-afflicted aged. While the quality and cost of care at 'lower life expectancy' levels - when most people were dying from circulation/heart diseases and, if they survived those, then of cancercould be sustained in affluent societies, dementia and related chronic diseases/conditions have proved extremely difficult and costly. Neither families nor medical facilities, nor even the expanding added care programs, are capable of providing adequate and effective care; added care often being required on a $24 / 7$ basis by qualified staff. Similarly, loneliness and social isolation pose a growing, as well as a widening, problem, because they are reinforced by communication difficulties (often coming with illness), mobility limitations, lack of facilities, and - last but not least - decreasing family networks combined with high mobility of children and family members. Impoverishment has hit the ageing population not only as a result of limitations to welfare budgets, but also due to the financial vulnerability of the aged: they are much less capable of managing their finances, become vulnerable to fraud, and are frequently exploited by unscrupulous care providers. These factors contribute to the rapidly widening 
'dependency syndrome' - declining capacity of the aged to sustain their autonomy - which quickly translates into care needs and costs, as well as a growing frustration and anger among the dependent aged, whose dignity is reduced.

Perhaps the most widely publicised-especially at a time of intensified deficit fears and budgetary strains - are the problems related to, and generated by, workforce shrinking and pension costs. They concern, above all, the shrinking and ageing labour force and the related increase in the 'dependency ratio' and pension burden. ${ }^{3}$ These problems - in fact a whole galaxy of inter-related problemshave been well diagnosed and analysed. If unmitigated, they threaten the standard of living of new generations, as well as the integrity of governmental budgets (lowering revenue, a declining tax base and wealth generation, increasing budgetary costs, etc.) (e.g. Bloom et al. 2011; Harper and Hamblin 2014; Commonwealth of Australia 2015).

Closely linked is the problem of spiralling welfare (including aged care and health) expectations and costs. The historically expanding welfare state generates its own self-propelling - and unsustainable, according to some critics-dynamics. At the core are growing welfare ('social') rights, regularly translated into entitlements, and their accompanying public expectation - particularly high in the baby boom generations - that these rights-cum-entitlements will expand in scope and quality. Such an expectation trajectory is fed by the culture and politics of welfare. The former creates norms and standards associated with the notion of social development: higher development $=$ more extensive, intensive and costly services. The latter (the 'demand side') feeds into the regular 'promises' of further expansion and improvement of services made by most parties and most political candidates in the process of electoral competitions (the 'supply side'). Both feed into the spiralling costs and into politically delegitimising effects ('broken promises' and declining trust provoking populist backlash). This is particularly dangerous in societies in which the aged welfare constituencies increase in absolute and relative terms. And it is

3 Thus, among EU members, the old age dependency ratio (number of people aged 65+ as a percentage of 20-64 years old) increased from 22 in the mid-1980s to 30 today, and is estimated to skyrocket to 55 in 2050 (United Nations 2013). 
dangerous because the very cost of welfare provisions, both generally and 'per unit', has been increasing, while the willingness to address this problem has not (e.g. Harper and Hamblin 2014; Torp 2013).

Spiralling welfare costs require prompt reactions and long-term mitigations. Otherwise welfare will transform into a 'burden' easily passed to the next generation (as public debt, pension obligations, anticipated cost of mitigation, etc.). This is easy-and dangerousbecause the issue of intergenerational equity (distribution of burdens) has not been absorbed into the political debates over social fairness and justice. Forthcoming generations, as cynics say, have no vote, and little political influence, and they are regularly burdened by unsustainable debts and mitigation costs (e.g. the costs of environmental mitigations). This is the case with the 'post-baby boom' generations in most Western societies. These generations face not only escalating welfare costs, an increasing 'dependency rate', and stagnating growth, but also the 'triple whammy' of mounting (public and private) debts, rising costs of living, and massive (though hard to calculate) burdens of environmental modifications. It is as if the ageing baby boomers in advanced societies have lost not only the capacity for anticipation, but also a sense of what is fair to their descendants.

The fourth set of problems of ageing concerns the costs and burdens of health care. These deserve a special mention because of their magnitude and rate of acceleration-higher than other welfare costs - as well as their declining manageability. The fast acceleration is the result of expanding expectations and demands, as well asand increasingly - the changing nature of ageing chronic conditions (like dementia). Ageing chronic conditions are those that cannot be cured, and require expensive treatment (e.g. Alzheimer Disease International 2014). Moreover, hopes of a prolonged healthy life, due to 'morbidity and mortality compression', now appear to have been exaggerated. The 'market' cost-inflation is also relevant: costly medicines, costly procedures, costly care, all resulting from the demand for high-cost 'niche' treatments (for the affluent aged) becoming a 'mass' expectation and demand.

With the ageing of the labour force, there is an accompanying problem of declining entrepreneurialism, innovativeness and productivity, which affects the associated developmental dynamism of advanced societies. This danger has been recently and separately diagnosed in the most rapidly ageing societies, such as Japan and South Korea, 
and in the Western advanced societies ('secular stagnation'). It seems that developed societies enter an unexpected slow-down in their economic dynamism that is, at least partly, related to ageing. They tend to become less dynamic and innovative, and more conservative and routine-prone than younger societies with youthful and expanding labour forces. That poses a number of problems, especially in the context of competitive globalisation.

One should also point to the problems coded into the fashionablebut seldom effective - mitigation strategy labelled, variously, 'familyfriendly', 'fertility-raising' or 'pronatalist'. Such strategies consist of creating incentives to have more children through 'revaluing the traditional roles' of women as mothers (the domain of the conservatives) and/or offering payments, services and facilitations to families with children. While the unwanted side-effects, wrong targeting and (dubious) cost-effectiveness of such strategies have been widely discussed, the unintended consequences and 'ironic side-effects' deserve attention. Perhaps the most damaging unintended consequence is the reduction of opportunities for women - opportunities for careers, self-realisation and the financial independence and dignity associated with them. Poorly designed pronatal policies may also undermine the very 'medicine' for workforce depletion, namely labour force participation by women (e.g. Harper 2006).

Finally, one should mention the sociocultural changes that accompany ageing. While it is fashionable to stress the advantages and benefits of ageing - declining criminality and violence, peaceful conservatism, etc. - the problems associated with those very tendencies should also be kept in mind. Ageing societies turn more conservative and more crime/violence fearing. This may reduce aggressive behaviour, but also increases the irrational fear of crime-and makes pressures for (inevitably expensive and often socially divisive) security measures, such as gated communities, harder to resist. Conservatism of age typically aids conservative parties, and spawns conservative policies that cement the status quo and reduce the pressures for early, costly, but necessary reforms. Yet such reforms are essential for effective social and political adjustment.

This brings us to the central topic of effective policy strategies. Such strategies, we argue, have to be 'learned', rather than 'invented'. They work better when adopted from successful 'policy leaders', 
rather than derived from party ideologies under pressure of crises. Obviously, the effective strategies have to be complex and systemiclike the problems themselves - and must combine preventive, mitigating and adjusting measures. Perhaps most importantly, they should be bi-partisan and long-term strategies that are propelled by prudent anticipation backed by social science, rather than short-term ('reactive') political opportunism that gets hold of political parties competing for votes in greying electorates. The 'should' in the last sentence is to be interpreted as advocacy for 'best practice' and for 'successful/effective outcomes'. I want to argue that the strategic approach to the problem of an ageing society will be improved by monitoring diverse policy outcomes and by learning from 'the relative successes' of such societies as Australia.

\section{The Australian strategy: '4Ps'}

Australian decision-makers, it is argued here, combine mitigation with adaptation in a strategy - referred to as ' 3 Ps' (see Commonwealth of Australia 2002, 2007, 2010 and 2015) - that proves comprehensive and effective in mitigating the dangers of ageing and countering the key anxiety-generating problems of an ageing society. This effectiveness is highlighted in a comparison with Poland, a society that faces wider and more serious challenges related to population ageing, and, at the same time, a society that illustrates the broader applicability of the Australian strategic model template (expanded to 4Ps). The '4Ps' of the strategy's shorthand name stand for the four elements of the policy template: people, productivity, participation and (added) provisions. The first three are well known, and have been discussed in previous Intergenerational Reports (Commonwealth of Australia 2002, 2007, 2010 and 2015).

It should be stressed that the 4Ps strategy is by no means a problem-free 'model ideal', or that the policies pursued by Australian governments are necessarily successful in implementing the model template. Rather, we argue that the policy strategy outlined below: (i) addresses the key challenges, problems and threats posed by ageing; (ii) does this in a comprehensive and sustainable manner by combining modification with adaptation; and (iii) has been partly but successfully 'tested' through an application that has reduced the scope of some problems. 
Therefore, we can learn from this relative success by generalising the strategy - or rather those elements that seem to be most important for successful mitigations and adaptations. Such strategic policy 'model templates', though, it should be remembered, can never be copied 'verbatim' without appropriate adjustments. Rather, implementation requires careful adaptation to the 'local idiom' - careful grafting rather than mechanical copying.

\section{Population: Rejuvenating immigration and immigrant integration}

This is the most important and the most effective element of the proposed strategic model template. Rejuvenating immigration — which has to be controlled and selective to play this role - is rare and difficult to sustain. Moreover, in order to 'work' as a 'moderator of ageing', it has to be backed by policies facilitating the integrative adaptation of immigrants; this is labelled '(integrative) multiculturalism' in Australia (e.g. McDonald and Kippen 200la).

Australia is not only a high-immigration society, but also a permanent-, selected- and young-immigration society. Since 2005, immigration levels have increased to around 220,000 per annum-reaching around 300,000 in 2008-09 and then declining again to 150,000180,000 - adding nearly 1 per cent of the total population per year. Most of these immigrants are selected for desirable skills, education and swift integration into the labour force and society. Importantly, nearly nine out of every 10 immigrants are aged under 40, with the median age within the 20-24 range. A growing proportion of immigrants come through Australian educational institutions, which facilitates social and economic integration and high incomes. The key facilitator of swift integration, though, is a strategy of multiculturalism that encourages integration, reduces mal-integration, and minimises discrimination. Altogether, this immigration-cum-integration strategy provides the main and most effective mitigation of the problems of ageing, though its maintenance becomes more difficult with the less-controlled inflow of immigrants and refugees from less developed regions and their more difficult experiences of integration. Nevertheless, population projections - based on current/recent migration, fertility and 
mortality rates - show a steady (1.3 per cent) and balanced growth of population, with a slow rate of ageing, and the dependency ratio falling gradually from about 4.5 today to about 2.7 in the $2050 \mathrm{~s}$.

Poland represents a very different pattern with very low fertility, prevailing out-migration and medium-level unemployment - all ripe for policy reforms. The out-migration of young and skilled men and young and highly educated women, in particular, exacerbate the problems caused by the process of ageing-cum-labour force depletion. The greatest 'population loss' has been in the 24-29 age group-among men with secondary and vocational education and among women with tertiary education. This is why the old age dependency ratio, which at present is not much different from Australia's (20-22 per cent) is expected to grow to 55 per cent in the next generation - a level similar to that anticipated in Germany, Italy and Spain (Okólski and Topińska 2012; The Economist 2009).

Yet, increasing immigration from the East gives Poland wide scope for policy manoeuvres. With fast growth (over 3 per cent), rapidly increasing living standards and declining unemployment, Poland has become an attractive destination to her eastern neighbours, especially Ukraine - a country experiencing economic and political crises and with a much lower standard of living. Ukraine and Belarus have similar languages and cultures and can count on the sympathy of Polish people, which facilitates integration. Moreover, Poland harbours residues of the multiculturalism it inherited from the 16th18th-century Jagiellonian Commonwealth with similarities to the Australian 'integrative multiculturalism', which can therefore serve as a moral political idiom in legitimising mass immigration.

\section{Productivity: Monitoring and sustaining high efficiency}

The negative effects of a shrinking labour force can be effectively mitigated, as the Australian example shows, by monitoring and promoting productivity increases. The key role of the Australian Productivity Commission and Australian Workforce and Productivity Agency in monitoring productivity nationwide, and the role of reforms increasing the productivity of the (shrinking) labour force have been discussed widely in the policy literature. Here we would like to stress the overall direction of the reforms, including 'productivity 
agreements' replacing 'workplace warfare', and the adaptive reforms of education (including mass upskilling of the workforce) providing a backbone for productivity boosting reforms that have proved so crucial in sustaining economic growth, income increases and a high standard of living.

The key component of the productivity increases (between 1.5 per cent and 2.2 per cent per year) in Australia has in recent decades been growing labour productivity. This has been sustained by reforms that boost competition, by harnessing innovations, absorbing new technologies and utilising as a springboard the educational revolution that accompanied a shift in production towards the service sector and its high-tech, high-skill end. Capital productivity, by contrast, has been declining, mainly because of massive investment in the declining mining/mineral boom. The success in increasing labour productivity - through a mixture of labour market and workplace reforms, education/training, and support for innovation-indicates that it could become an effective 'cushion' against the ageing-related shrinking of productive labour.

The danger of declining productivity - be it due to the fading impact of reforms, the declining inflow of educated and skilled migrants, high ('boom-windfall') profitability, low unemployment or high/ uncompetitive labour costs - can be countered only by the continuous monitoring and boosting of productivity across all sectors of the economy, as well as by promoting a 'culture of high productivity' across society. The latter encounters two serious barriers: the rising tide of conservatism, partly as a result of the ageing population, and the pressures of high consumption and leisure expectations of the (ageing) baby boom generation. In this context, one should stress that the highest productivity growth in Australia occurred in the post-World War II decades and was achieved by a highly liberal war generation. Since the beginning of this century, this growth has floundered; Australia is ranked 50th on total productivity growth. The generational shift, a conservative-complacent cultural wave, and the mining boom that brought with it an enormous jump in investment and windfall profitability, all lowered the reformist pressures and growth in productivity, while an increased inflow of educated and skilled immigrants helped to sustain productivity increases. 
Poland is well placed in respect of productivity growth. Labour productivity in Poland remains much lower than in Australia, but it has also been increasing much faster (around 25 per cent in the last five years, compared with around 6 per cent in the last five years in Australia) (PRP 2013; Commonwealth of Australia 2015; Trading Economics 2014). This growth is high in both industry and services, coincides with increasing education and technological absorption, and follows the steady increase in exports. Most importantly, this growth is seen as sustainable, reflecting intense reforms and steady industrial-cumservice growth, and therefore opens the way for effective cushioning of the effects of ageing in the forthcoming decades. However, the 'productivity dividend' badly needs social-political reinforcement in the form of a 'social contract' between the government, trade unions, and employer organisations. Such a contract - followed by reformsshould not be difficult to develop considering the still strong residues of national solidarism created by the Solidarity movement and postcommunist reforms.

As Devictor (2012: 6) points out:

Experience suggests that increasing labour productivity is also a complex, multidimensional task. It involves efforts in areas such as: the quality of education (basic education, professional training, higher education, life-long learning, etc.); the business environment, to support job creation and innovation; labour regulations, to help jobs move towards more productive and growing firms; economic transformation in sectors where productivity remains low, including agriculture; etc. This is an agenda that needs to be pursued regardless of demographic trends, but that the aging of society makes even more pressing.

\section{Participation, employment and unemployment}

One of the successful measures expanding the labour force and reducing the 'socioeconomic' impact of ageing-that typically brings a decline in the number of working persons - has been the high participation rate. Australia had one of the highest participation rates of people aged 15+ among the OECD countries in 2013, and this rate is predicted to stay at a high level for the next 40 years, while migrant participation will be falling, and female participation increasing. Australian women have doubled their proportion in the labour force within one generation (to the current 59-65 per cent in 
all adult cohorts) and this growth is likely to continue. Another aspect of the Australian strategy of cushioning the impact of ageing through participation is the gradual extension of working time through incentives to professionals to continue their work, and the phasing in of the increase of the retirement age to 70 (by 2030). Thus the steady increase in participation rates, combined with prolonged employment, offers to Australian society another buffer against the impact of sudden ageing and its labour- and growth-depleting consequences.

The biggest challenge comes from another aspect of participation: hours worked. The volume of work and the level of unemployment have a large impact on economic outcomes; and that forms a formidable challenge, because the number of hours worked has been falling with a shift to part-time and temporary employment, especially among women and older workers. Women often prefer part-time employment because it is easier to square with their home/parental duties. Older workers are tempted to ease their load, especially when it does not adversely affect their superannuation funds and pensions. The decline in working hours is likely to continue with the expansion of the female and old labour forces, thus threatening the integrity of the participation strategy.

A similar threat comes from increasing unemployment, or rather decreasing employment. 'Postmodern' (increasingly service) economies shed low-skill and secure jobs, and create more fickle jobs demanding high social and technical skills (see Summers 2014). This means that unemployment is likely to become a chronic condition for large lowskill segments of 'postmodernising' populations, even in countries like Australia, where the labour force is highly skilled, flexible and mobile. In the light of trends in the most developed societies, the assumption of low (5 per cent) and stable unemployment in the Australian Intergenerational Report must strike us as highly optimistic - or as a harbinger of increasing public employment (straining the welfare budget).

Participation rates in Poland are lower than in Australia, doubtless due to more rapid ageing and higher unemployment (see Table 1). The share of people 65+ is expected to nearly double by 2030, and almost triple by 2050, while the trend in participation in the 15-64 age cohorts had been less favourable, declining until 2007-08 and then increasing only slightly. But these trends are reversible, and, in fact, 
are starting to change. Participation rates, especially among women, has stabilised on the low level, and it is hard to predict how it is likely to be affected by the newly introduced child bonuses and by the promised lowering of the retirement age. Thus, while unemployment has been falling and the number of hours worked has been increasing, one should not assume the continuing increase trend in workforce participation rates in Poland, especially among women.

This opens the way for many-fold reforms boosting participation even further. The current (and minor) rise in female participation can be easily reinforced because it has followed a rapid increase in female education and-though less strong-growth in employment opportunities in the public sector. That may bode well for the future of female participation in Poland - and for the cushioning effect against ageing. Second, as shown by the experience of almost all developed societies, 'if you live longer, you have to work longer'. Government attempts to increase the retirement age have been quite successful, though they follow disastrous incentives for early retirement of 'uniformed services', and an equally imprudent decision by the opposition Law and Justice (PiS) party to 'restore' - when in government - the 'old' retirement age of 60 (women) and 65 (men). The biggest challenge is to increase participation by older (over 55) workers. Only 35 per cent of 55-64-year-old persons in Poland are employed (compared with the EU average of 51); this requires facilitations (such as upskilling) and incentives (such as tax breaks).

\section{Provisions: Pensions and superannuation funds}

The fourth $\mathrm{P}$ is most challenging in its design and most difficult in its implementation. It consists of policies that secure financial and fiscal sustainability for old-age pensions and welfare services, and that implies not only balanced budgets (extremely rare among developed societies) but also savings preventing future financial squeezes and over-runs. In negative terms, such policies prevent the impoverishment of, and degradation of services for, the aged, including health/medical services. When faced with the unanticipated and rapid ageing of populations, governments face the challenge of expanding old-age pension provisions without creating deficits, debts and budgetary strains that, in turn, easily create or fuel social divisions and political tensions (e.g. Kendig et al. 2013). In Japan, a country that best 
illustrates the escalating costs of old-age pensions and aged care, the connected health and care costs-left untackled until recently-have been increasing geometrically: 6 per cent of GNP in 1970, 18 per cent in 1992, 22 per cent in 2013, and are expected to have increased to 27 per cent by 2025 (Ogawa 2014). Australia has largely avoided such dramatic fiscal pressures, though one estimate of budgetary deficit related to old-age pensions and aged-care services has been $\$ 40$ billion and $\$ 13$ billion respectively.

Broadly defined, provisions also include (i) financial adaptation (cum-cost-containment) of the growing number of aged, increasing longevity, and growing expectations of the ageing baby boomers; and (ii) the expansion of aged care and services, including the adaptation of the entire living environment to the specific needs of the aged. It ranges from trivial- like accessible housing and parking - to more sophisticated, such as easily driven cars, internet medicine, meanstested concessions and sophisticated information provision. Such services work if they are driven by the principle of widening and lengthening participation and the social benefits that participation brings to society and individuals, rather than by the self-serving needs-assessment of professional workers, who often create perverse incentives for dependency and the associated budget strain.

Australia has a relatively small deficit (2.5 per cent of GDP) and net public debt (around 15 per cent of GDP). The government has managed to contain the escalating costs through the monitoring and topping up of pension funds (including the \$109 billion Future Fund to cover public service pensions), the building up of a strong ( $\$ 1.8$ trillion) superannuation system, with compulsory contributions rising to 12 per cent, the creation of private-public 'partnerships' in service provision $\left(\mathrm{HACC}^{4}, \mathrm{PACE}^{5}\right)$, the expansion of the 'user pays' principle combined with phased-in means-testing, and the expansion of market-regulated old-age services. To this policy set may be added a facilitation-cum-incentive for co-funding old age services by pensioners with high-value but 'frozen' assets through various forms of 'liquidification', such as reverse mortgages.

4 Home and Community Care.

5 Positive Action towards Career Engagement. 
Poland, like most EU economies, is less prepared for a massive increase in old-age provisions (PRP 2013). The pension system has been reformed, but the country's superannuation-like open pension funds (OFE) have been emasculated. As Devictor (2012: 10) notes:

The funding of the pensions system is obviously a key concern. Poland went through a full restructuring of its system over a decade ago and is reasonably well prepared. Yet, there remain uncertainties over the pension levels that will be provided in the medium-term. Under Poland's notional account pension system accumulated contributions are divided by life expectancy: thus, as life expectancy increases, benefits automatically decrease (unless people retire later) and the question is whether they will remain adequate. Some countries, such as Sweden, Italy, or Latvia, are also grappling with these issues.

Restoring private retirement funds, together with providing incentives (tax and otherwise) for saving for retirement, would not only restore balance between the 'three pillars' of old-age financial provisions (public pensions, superannuation, dedicated private savings), but also reduce future budgetary burdens, which are unfairly and unrealistically high at present. This can be done in an 'Australian way', through a mixture of incentives and regulations, partly because consumption levels in Poland are very high, and are unlikely to be lowered by incentives to save more and by regulations facilitating saving for retirement.

Is there a place for the "Fifth $\mathrm{P}^{\prime}$ ", namely pronatalist measures, understood as policy designed to increase fertility rates and promote parenthood? The answer-based on the experiences of Australia, other developed societies and Poland-seems to be a qualified 'yes'. Australia may be seen as a moderate success in increasing fertility rates without high costs and 'perverse incentives' that reduce employment (participation) of women. But one has to keep in mind the reservations and qualifications mentioned above. Pronatal policies are very expensive, their effectiveness is dubious, and they often produce unintended consequences, some of them quite perverse (like reducing procreation choices or discouraging women from seeking employment). Taxing the childless (discredited in communist Poland), reducing access to contraceptives (discredited in communist Romania) or direct payments to mothers (discredited everywhere) are examples of poor strategies and policies pregnant with perverse effects. 
They work only as a 'part of the policy mix', when designed in a way that limits perverse effects (e.g. welfare dependency, discouragement of employment) - and, obviously, when they are affordable and do not unduly 'burden' employers and/or the next generation. Examples of such well-designed measures include tax breaks for child-rearing expenses, parental leave, subsidised child care, etc. They are flexible, easily adjustable, and - most importantly - they have proven effective in raising fertility without reducing freedom and/or breaking government budgets.

\section{Conclusions: Facing the challenges of ageing societies}

The meta-principle of policy strategy suggested here may be formulated as 'follow the best practice' and 'emulate success'. Australia's response to population ageing seem to closely approximate such a best practice - it is comprehensive, complex, sustainable, longterm - and it has shown considerable success in facing the numerous challenges of an ageing society. Hence this attempt to 'generalise it' and 'forge out of it' a general strategic model that can be applicable to other highly developed societies, as exemplified by Poland.

Let us summarise the key elements of the complex strategy for facing the challenges of an ageing society that we have 'extracted' (necessarily selectively) from the Australian strategic policy set under the label of '4Ps':

- systematic monitoring of 'old age problems' (poor health, loneliness, social isolation, dependency, impoverishment)their scope, intensity and social distribution;

- systematic monitoring of 'ageing society problems': economic dynamism, shrinking of working populations combined with increasing old age dependency ratios (dependent/working), and increasing generational 'burdens'; rising costs of welfare and aged care; rapidly increasing health costs, formation and mobilisation of 'grey lobbies', and rising conservatism;

- selective and rejuvenating immigration combined with integrative multiculturalism that includes incentives for, and facilitations of, swift employment and social engagement; 
- systematic monitoring and promotion of productivity combined with reforms that boost productivity, such as 'productivity agreements' and productivity enhancement (education, skilling, investment in technologies, etc.);

- encouraging high labour force participation, especially among women and older workers, as well as encouraging longer employment, especially among highly skilled workers and professionals, and reducing unemployment, especially among young people;

- building up the self-funding component of pensions through strengthening of superannuation and encouragement of individual saving for old age. This also includes incentives for co-funding of old-age pensions and services from inheritable assets;

- containment of welfare and old-age care costs through the expanding use of 'partnerships' between families, volunteers, private service providers, philanthropic organisations and government bodies in provision and through the continuous rationalisation (qualitative) of old-age care;

- adaptation of the environment and 'living infrastructure' (houses, flats, roads, cars, shops, public spaces) for the use of all age cohorts.

The success of all of these strategies, it seems, depends on three factors. The first consists of stringing all these elements together, reducing inconsistencies, and 'testing' the model in practice in order to identify its 'sticking points', strengths and weaknesses early. The second-mentioned only briefly but extremely importantconsists of adapting the strategic 'model' to the specific conditions of place and time. In social policy, as in transplant surgery, grafts that are not carefully prepared are often rejected. The third condition, hardly mentioned above, concerns the political presentation and promotion that, in turn, secure systematic implementation. This is to a large extent dependent on public information, education and systematic generation of political approval and good will. Public information and education, as the practice shows, are easily provided in highly educated advanced societies. The biggest barriers are short-termismthe best friend of demagogic opportunists - and sectional (ideological generational, age group, class, partisan) biases. When faced with the problems of an ageing society, conservative politicians tend to resort to 'traditionalist' strategies, such as 'pronatalism' aimed at 'restoring' traditional gender roles and identities, often at the expense of women's rights - an obvious illusion in the contemporary world. 
Socialists often want to return to the communist-era restrictions on individual liberties and human rights by promoting state direct interventions, and they often promote popular but expensive policies with dubious returns (e.g. shortening working time, 'baby bonuses', etc.). Liberal-minded politicians are prone to another illusory beliefthat it is enough to 'restore' individual responsibility, restrict public welfare, deregulate, cut entitlements and build up 'market driven individualism' in order to encourage rational conduct and the accompanied social-demographic balance. Such a strategy, as can be seen in Europe and America, does not work either. Instead, this kind of strategy exacerbates and masks, rather than mitigates, the problems of an ageing society. So do the strategies routinely embraced by the socialist left - expansion of services at the cost of mounting deficits and crippling debts, increasing taxation and, generally, pushing the burden onto the shoulders of coming generations. Therefore, the best chance of success is offered by removing policy strategies from the realm of ideological and partisan competition, making them supraideological (based on proven success), bi-partisan, or at least by removing them from the agenda of daily partisan contests.

\section{References}

Alzheimer Disease International (2014). Five Country Alzheimer's Disease Survey. Report of Key Findings. www.alz.co.uk/research/ statistics. Accessed March 2015.

Beard John, Biggs Simon, Bloom David, Fried Linda, Hogan Paul, Kalache Alexandre and Olshansky Jay (Eds) (2011). Global Population Ageing: Peril or Promise. Geneva: World Economic Forum.

Bloom David, Boersch-Suppan Axel, McGee Patrick and Seike Atsushi (2011). Population Aging: Facts, Challenges, Responses. PGDA Working Paper No. 7. Program on the Global Demography of Aging, www3.weforum.org/docs/WEF_GAC_GlobalPopulation Ageing_Report_2012.pdf. Accessed December 2014.

Cardwell John (2006). Demographic Transition Theory. Dordrecht: Springer.

Devictor Xavier (2012). Poland: Aging and the Economy. Opinion piece, 14 June, The World Bank. www.worldbank.org/en/news/ opinion/2012/06/14/poland-aging-and-the-economy. 
Goldstone Jack, Kaufmann Eric and Toft Monica Duffy (eds) (2013). Political Demography. How Population Changes Are Reshaping International Security and National Politics. Oxford: Oxford University Press.

Gray Matthew, Qu Lixia and Weston Ruth (2008). Fertility and Family Policy in Australia. Research Paper No. 41, Australian Institute of Family Studies.

Harper Sarah (2006). Ageing Societies: Myths, Challenges and Opportunities. London: Hodder Arnold.

Harper Sarah and Hamblin Kate (Eds) (2014). International Handbook of Ageing and Public Policy. London: Edward Elgar.

Commonwealth of Australia (2002). Intergenerational Report: 2002-03. Canberra: Department of Treasury.

Commonwealth of Australia (2007). Intergenerational Report: 2007. Canberra: Department of Treasury.

Commonwealth of Australia (2010). Australia to 2050: Future Challenges. The 2010 Intergenerational Report. Canberra: Department of Treasury.

Commonwealth of Australia (2015). 2015 Intergenerational Report: Australia in 2055. Canberra: Department of Treasury. www. treasury.gov.au/PublicationsAndMedia/Publications/2015/2015Intergenerational-Report. Accessed March 2015.

Department of Treasury (n.d.). Australia's Demographic Challengesthe economic implications of an ageing population. demographics. treasury.gov.au/content/_download/australias_demographic_ challenges/html/adc-04.asp. Accessed March 2015.

Kaufmann Eric (2011). Shall the Religious Inherit the Earth: Demography and Politics in the Twenty-first Century? London: Profile Books.

Kendig Hal, Wells Yvonne and O'Laughlin Kate (2013). Australian baby boomers face retirement during the global financial crisis, Journal of Ageing and Public Policy, 25: 264-280.

Lee Ronald (2003). The Demographic Transition: Three Centuries of Fundamental Change, Journal of Economic Perspectives, 17(Fall): 167-190. 
McDonald Peter and Kippen Rebecca (1999). Ageing: the social and demographic dimensions. In Policy Implications of the Ageing of Australia's Population, Conference Proceedings, 18-19 March 1998, Productivity Commission and Melbourne Institute of Applied Economic and Social Research, pp. 47-70.

McDonald Peter and Kippen Rebecca (2001a). The impact of immigration on the ageing of Australia's population. In M Siddique (Ed) International Migration into the 21st Century, Cheltenham: Edward Elgar, pp. 153-177.

McDonald Peter and Kippen Rebecca (2001b). Labour supply prospects in 16 developed countries, 2000-2050, Population and Development Review, 27(1): 1-32.

Ogawa Naohiro (2014). Population Ageing in Japan and Its Financial Consequences. Paper presented at the session on Population Ageing Academy of the Social Sciences in Australia, Canberra, 11 November 2014.

Okólski Marek and Topińska Irena (2012). Social Impact of Emigration and Rural-Urban Migration in Central and Eastern Europe, Final Country Report-Poland. Berlin: GVG.

Organisation for Economic Co-operation and Development (OECD) (2013). Demographic Transition and an Ageing Society: Implications for local labour markets in Poland, Report. www.oecd.org/cfe/leed/ Poland\%20Report_V8.1\%20FINAL.pdf.

Pracodawcy Rzeczypospolitej Polskiej (PRP) (2013). Starzejace sie spoleczenstwo jako wyzwanie ekonomiczne dla europejskich gospodarek, Raport, Pracodawcy Rzeczypospolitej Polskiej. docplayer.pl/4071703-Raport-starzejace-sie-spoleczenstwo-jakowyzwanie-ekonomiczne-dla-europeiskich-gospodarek.html. Accessed 2 October 2015.

Productivity Commission (2013). An Ageing Australia: Preparing for the future. Research Report. Canberra: Productivity Commission.

Summers Lawrence H (2014). US Economic Prospects: Secular Stagnation, Hysteresis, and the Zero Lower Bound, Business Economics, 49(2): 65-73. 
The Economist (2014). Age Invaders, 26 April. www.economist.com/ news/briefings/21601248-generation-old-people-about-changeglobal-economy-they-will-not-all-do-so.

The Economist (2009). Healthcare Strategies for an Ageing Society, Economist Intelligence Unit, 7 May.

Torp Cornelius (Ed) (2013). Ageing in the 20th Century. Cambridge: Cambridge University Press.

Trading Economics (2014). Poland Productivity. www.trading economics.com/poland/productivity. Accessed March 2015.

United Nations (2001). World Population Ageing: 1950-2050. New York: Department of Economic and Social Affairs Population Division.

United Nations (2013). World Population Ageing 2013, New York: Department of Economic and Social Affairs Population Division. www.un.org/en/development/desa/population/publications/pdf/ ageing/WorldPopulationAgeing2013.pdf. Accessed March 2015.

\section{Websites}

Alzheimer Disease International, www.alz.co.uk/research/statistics. Accessed March 2015.

Dementia and Alzheimer Disease, www.alzheimer-europe.org/ Dementia. Accessed March 2015.

HACC-Home and Community Care Program, www.health.wa.gov.au/ hacc/home/whatis.cfm. Accessed March 2015.

Knoema, knoema.com/PDYGTH/labour-productivity-growth-in-thetotal-economy? country $=1000240$-poland. Accessed March 2015.

PACE, www.ncbi.nlm.nih.gov/pubmed/9033525. Accessed March 2015.

Polskie Towarzystwo Alzheimerowskie. alzheimerpolska.pl.

Wikipedia, Population Ageing, en.wikipedia.org/wiki/Population_ ageing. Accessed March 2014. 
This text is taken from Population Ageing and Australia's Future, edited by Hal Kendig, Peter McDonald and John Piggott, published 2016 by ANU Press, The Australian National University, Canberra, Australia. 